\title{
Research on Organizational Human Resources Knowledge Structure Model Based on the Perspective of System Engineering Methodology
}

\author{
Lei Zhanbo*, Li Qiongyao \\ School of Public Policy and Administration, Xi'an Jiaotong University, Xi'an, China \\ Email address: \\ leizhanb@mail.xjtu.edu.cn (Lei Zhanbo),Liqiongyao@mail.xjtu.edu.cn (Li Qiongyao) \\ ${ }^{*}$ Corresponding author
}

To cite this article:

Lei Zhanbo, Li Qiongyao. Research on Organizational Human Resources Knowledge Structure Model Based on the Perspective of System Engineering Methodology. Social Sciences. Vol. 10, No. 2, 2021, pp. 48-57. doi: 10.11648/j.ss.20211002.12

Received: March 8, 2021; Accepted: March 22, 2021; Published: March 30, 2021

\begin{abstract}
The importance of studying organizational human resources knowledge structure is self-evident for organizational human resources selection and training. It is also significant for organizations to conduct knowledge management and gain competitive advantages. In this way, how do we understand the relationship among the knowledge structure owned by the organizational human resources, the functional levels and the business process situated, and the logical thinking applied? This is what this paper will further explore. This paper aims to help organizations define the demand structure and distribution characteristics of human resources' functional knowledge, business process knowledge, environmental knowledge, logical thinking knowledge, based on the situated functional levels of human resources. Furthermore, it endeavors to provide a framework for determining the knowledge system and structure which are closely related to human resources selection and training. From the perspective of System Theory, each organization is an independent system. The work of any individual within the organization is one part of a system engineer. Naturally, system engineering methodology becomes its methodology. Based on the four-dimensional structure of system engineering methodology, this paper analyses human resources knowledge structure from the perspectives of function levels, environment, process and logic, and further constructs the organizational human resources knowledge four-dimensional structure model (HRKFDM). The knowledge of organizational human resources is closely related to business process, environmental conditions, function levels and thinking logic. The organizational HRKFDM shows that organizational human resources knowledge is made up with functional knowledge dimension, environmental knowledge dimension, process knowledge dimension, and logical knowledge dimension. In the problem-solving process with logical thinking and decision-making, human resources need to comprehensively use the functional knowledge, environmental knowledge, process knowledge and logical knowledge. In each knowledge dimension, the functional knowledge, environmental knowledge, process knowledge and logical knowledge requirements for grass-roots workers, middle-level workers, and senior workers follow trapezoidal distribution, yamagata distribution and trapezoidal distribution respectively. The organizational HRKFDM can be used as an important reference framework for promoting organizational learning, as well as an instruction for organizational learning, knowledge management, building a learning organization, and developing the core competence of an organization.
\end{abstract}

Keywords: Knowledge Structure, Human Resource Selection, Training, System Engineering Methodology, Model, Knowledge Management, Organizational Learning

\section{Introduction}

Organization Resource Basic Theory [1] considers the organic combination of employee's knowledge and ability as special resource for enterprises. It is an important factor affecting the competitive advantage of enterprises to pass specific knowledge to employees in specific positions through the knowledge management of micro activity process. As knowledge and abilities rely on human resources to work, the knowledge structure of human resources forms a critical strength of organizations' competitive advantage. Therefore, all organizations think highly of the study of human resources 
knowledge structure in management practice and maintain a good management of human resources knowledge structure.

A scientific and reasonable human resources knowledge structure is an essential basis for human resources selection and training. The focus of human resource selection has experienced a shift from vacant positions to organizational strategic objectives' assurance. In this process, competency has gradually become an important selection indicator. Spencer [2] regarded the evaluation competency as a vital factor to enhance the effectiveness of selection and succession. Zhao Shuming [3] constructed a multi-competency model involving necessary competency, differential competency and strategic competency through empirical studies. Zhang Qing [4] built a competency model with six processes based on strategy and values. Wang Chongming [5] used structural equation models to define manager competency consisted of management ability and management quality. Li Hongwei [6] constructed a five-dimensional quality model of personnel selection from the aspects of quality, skills, knowledge, background and ability. In the specific operation of human resource selection, Chen Yueru [7] and Liao Ming [8] suggested to divide human resources by levels and categories and determine selection method based on positions in order to enhance the matching between jobs and individuals.

Human resource training session is an important approach for organizations to cultivate talents. Many scholars have built models to enhance the systematicness of training. Zhao Shuming [9] proposed a training system model based on the effectiveness and systematicness of training. Li Ying [10] introduced a strategic thinking into training development activities and formed a strategic process model. Needs analysis and plans' making in training model are the premise of effective training. It has become a choice for many scholars to study the needs analysis in training founded on competency [11], personal factors [12], and performance [13]. Being an important evaluating factor within training plan, the training content should be combined with employee career development planning, organizational strategy objectives, and organizational resources. However, limited to the application of elementary training mode, the training content mostly stays in simple skills and emergency operations. So it is difficult to make a comprehensive and accurate training plan based on knowledge structure, qualities, and abilities. The current plans are random and lack of systematicness, which are unable to meet the needs of human resources.

Human resources knowledge structure is a critical factor in human resources selection and training. There are three viewpoints on knowledge structure, namely hierarchical network, feature comparison and concept combination. They all take knowledge content as basic elements and integrate them into knowledge structure. The literature focusing on knowledge structure mostly discussed the influence of knowledge structure on organizations, such as the different impacts of element knowledge and structure knowledge on enterprise competitive advantage [14, 15]. Other scholars studied the knowledge structure of different professionals. Qian Jianping [16] pointed out the variations on professional, fundamental, and relevant knowledge level among talents specialized in different intellectual property rights, and therefore, different training modes should be formed according to the needs. Liu Guangzhu [17] and Wang Hao [18] used quantitative methods to study the knowledge structure of periodical librarians and enterprise managers. These studies are often limited to a specific organization or field, lacking integrated and systematic studies on the theoretical level of knowledge structure system. Although studies on human resource training have already involved knowledge resources, while the importance of knowledge structure to organizational strategic change [19], core competence [20], and innovation performance [21-22] has gradually been paid attention to, few studies have linked the knowledge structure system with human resource selection and training and discussed the extent of matching. In short, the current studies on organizational human resources knowledge structure are mostly separated from those on human resources selection and training. They have not revealed the relationship among organizational human resources knowledge structure, the situated functional levels, business process, environment, and logical thinking.

However, from the perspective of system engineering, the work of any individual within the organization is one part of a system engineer in essence. Therefore, it is necessary to investigate it based on system engineering methodology. According to the four-dimensional structure of system engineering methodology and the process model of organizational human resources management proposed by Lei Zhanbo [23-25], this paper constructs the organizational human resources knowledge structure model consisted of functional knowledge dimension, environmental knowledge dimension, process knowledge dimension and logical knowledge dimension. After exploring each knowledge dimension, it demonstrates that the knowledge demand of grass-roots workers, mid-level workers, senior workers of each dimension follows trapezoidal distribution, yamagata distribution and trapezoidal distribution respectively. Therefore, the organizational human resources knowledge situation can be analyzed by the four-dimensional structure model, while human resources can be selected and trained based on their knowledge structure and distributions. This paper provides a scientific knowledge structure framework for organizations to determine the demand structure and characteristics of its human resource logical thinking knowledge, position environment knowledge, business process knowledge and functional knowledge based on the talents' professional positions, and then to determine the necessary knowledge and its structure for human resources selection and training.

\section{Definition of Organizational Human Resource Knowledge}

Knowledge is the description of facts and information or the skills acquired in education and practice, which is reflected in as the familiarity and mastery of their own jobs on human resources. Knowledge is carried and applied by human beings. Knowledge condensed in human resources is not chaotic, but 
hierarchical and systematic.

\section{Organizational Human Resource Knowledge Four-Dimensional Structure Model}

A. D. Hall three-dimensional structure system is the most influential system engineering methodology in the field of system engineering. The four-dimensional structure system (Figure 1) is developed based on A. D. Hall three-dimensional structure system. It considers environment as a new dimension, which is of same importance as knowledge, logic, and time dimensions. It emphasizes the importance of environmental analysis, strengthens the spatio-temporal connection, obviously reflects the influences of environmental and geographical factors, and conforms to the complex and changeable globalization context.

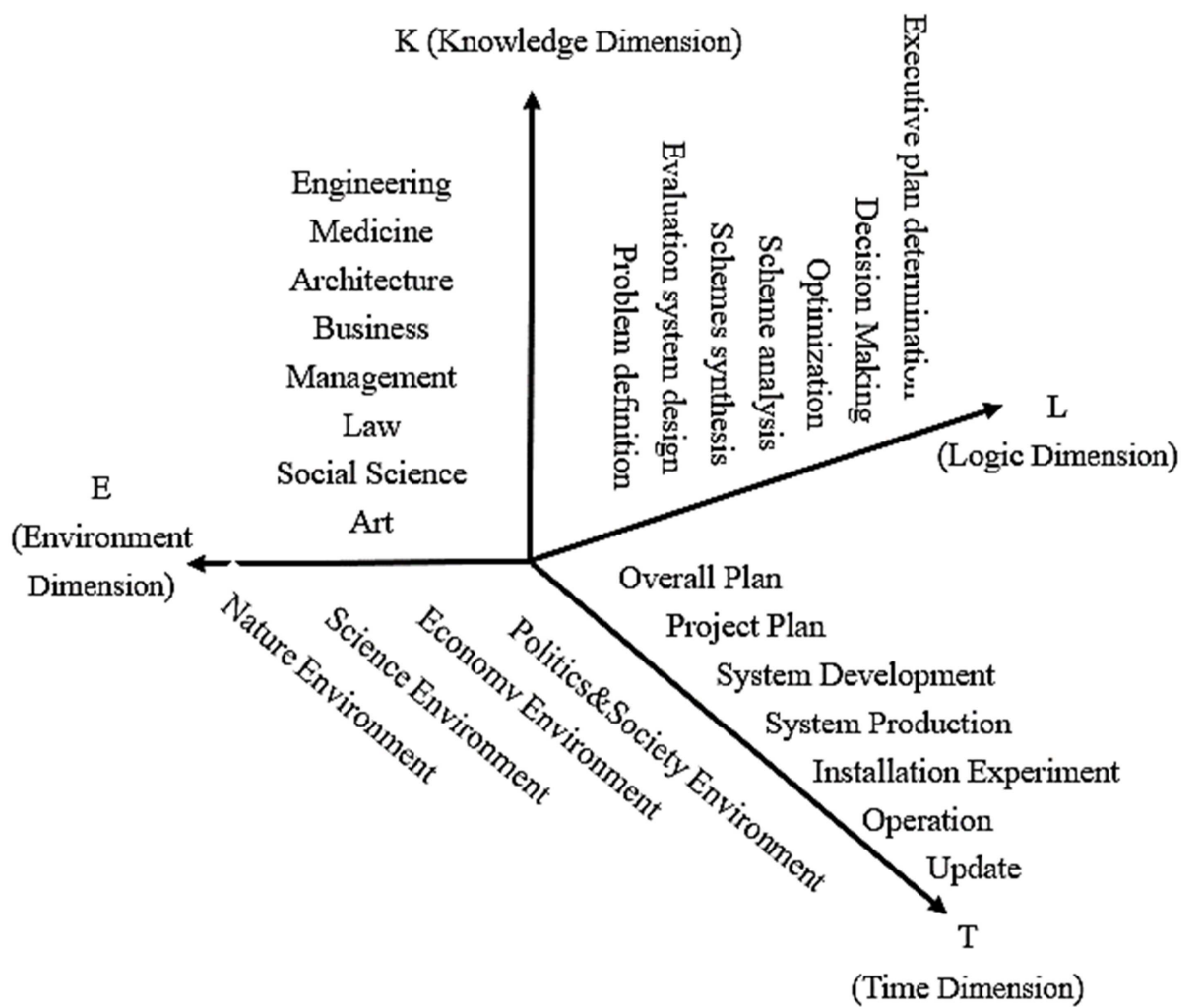

Figure 1. The four-dimensional structure of system engineering methodology.

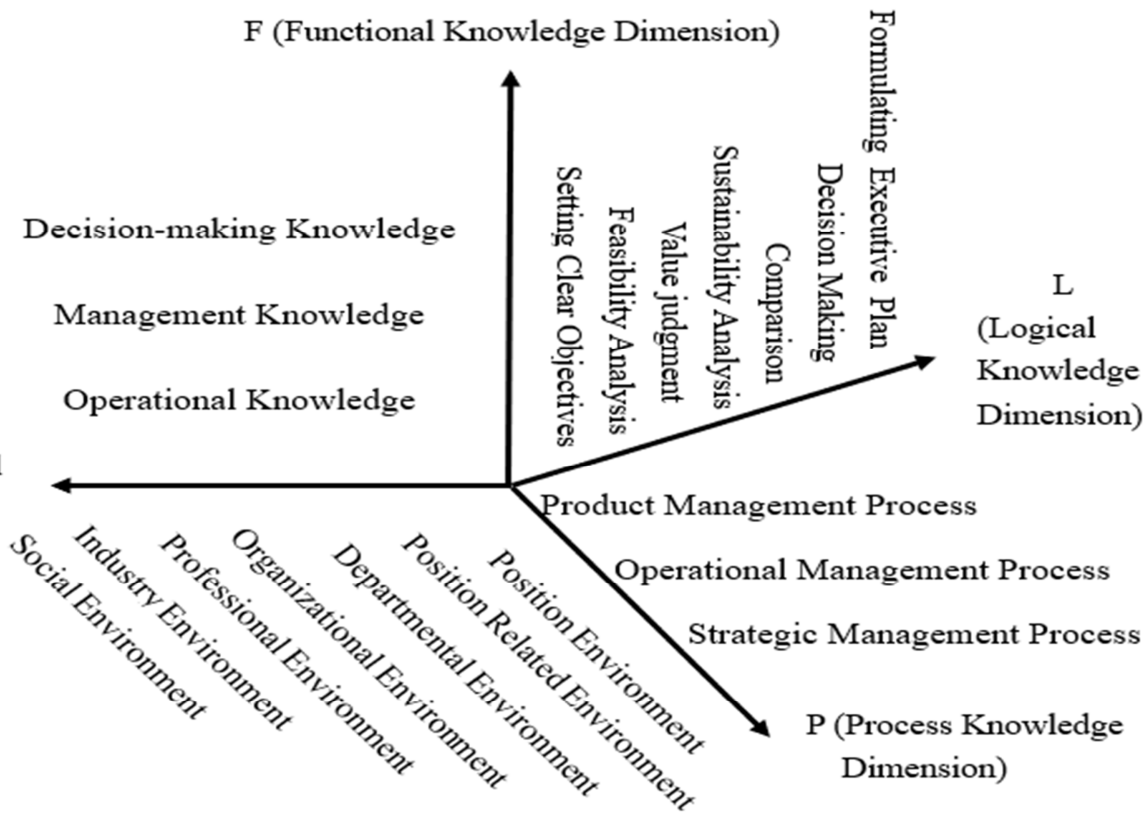

Figure 2. Organizational human resource knowledge four-dimensional structure model. 
According to the four-dimensional structure of system engineering methodology, four aspects of organizational human resources knowledge are mapped out. They are functional level knowledge, environmental knowledge, business process knowledge, and logical knowledge. Based on these four aspects, the organizational human resource knowledge four-dimensional structure model (Figure 2) is constructed. Functional level knowledge varies with the functional level of human resources. Environmental knowledge is affected by a series of micro and macro factors inside and outside the organization where human resources are located. Business process knowledge is what human resources learn when they are engaged in and handling different business processes. Logical knowledge refers to the correct logical mind-set of human resources gained when handling different business processes and completing positional functions. The organizational HRKFDM contributes to a dynamic and systematic methodology for the organizational human resources knowledge management, and it also enhances the pertinence and effectiveness of human resources selection and training.

\section{Connotation of Organizational HRKFDM}

Individual knowledge is a component of organizational knowledge. Individual knowledge can be divided into visible knowledge and invisible knowledge. It is necessary to strengthen visible knowledge and explore invisible knowledge to optimize organizational knowledge resources. Both the needs of organizational development and the needs of employees' career development require the construction of organizational human resources knowledge structural system to promote the hierarchy and the integrity of knowledge system. In the past, human resources training within organizations was merely a formality or lacking some systematicness. The organizational human resource knowledge four-dimensional structure system extracts the knowledge that human resources should have obtained as an independent unit for systematic research. In practice, this system contains universality and allows for adaptation to circumstances. It helps to determine the human resources knowledge needed in the organization based on the organization's functional level, business processes, environmental characteristics, and logical factors.

\subsection{Functional Knowledge Dimension}

The functional knowledge dimension reflects the knowledge that employees at different functional levels should master within the organization. Knowledge is people's understanding, judgment or skills obtained through learning, training or practice. The human resources knowledge that members of an organization should possess is relevant to their functions, roles and job levels in the organization. According to Yang Baiyin's knowledge holism, knowledge is divided into perceptual knowledge, conceptual knowledge and affectual knowledge gained from experiences, logical cognition and emotions [26, 27]. In actual human resources management, knowledge is divided into operational knowledge, management knowledge and decision-making knowledge based on level of organizational functions [25]. Different functional level knowledge can be combined with perceptual knowledge, conceptual knowledge and affectual knowledge, thus forming the connotation of functional knowledge dimension, as shown in table 1 [28].

Table 1. The specific contents of the functional knowledge dimension.

\begin{tabular}{|c|c|c|c|}
\hline Functional level & Perceptual knowledge & Conceptual knowledge & Affectual knowledge \\
\hline $\begin{array}{l}\text { Decision-making } \\
\text { knowledge }\end{array}$ & $\begin{array}{l}\text { Art of leadership, Decision-making ability, } \\
\text { Strategic planning ability }\end{array}$ & $\begin{array}{l}\text { Management theory, Management idea, } \\
\text { Policy }\end{array}$ & $\begin{array}{l}\text { Organizational vision, } \\
\text { Mission, Value }\end{array}$ \\
\hline Management knowledge & $\begin{array}{l}\text { Coordination ability, Plan arrangement } \\
\text { ability, Communication ability }\end{array}$ & $\begin{array}{l}\text { Rules and regulations, Technical } \\
\text { indicator, Management method }\end{array}$ & $\begin{array}{l}\text { Management passion, } \\
\text { Responsibility }\end{array}$ \\
\hline Operational Knowledge & $\begin{array}{l}\text { Know-how, Cooperation ability, } \\
\text { Communication ability }\end{array}$ & $\begin{array}{l}\text { Operational specification, Technical } \\
\text { explanations }\end{array}$ & $\begin{array}{l}\text { Operational attitude, Work } \\
\text { mood }\end{array}$ \\
\hline
\end{tabular}

Meanwhile, the quantity and quality of knowledge owned by members at different functional levels are different. Some individuals have high-end, leading-edge and extensive knowledge, while others only have relatively out-of-date, universal and procedural knowledge. Thus, the knowledge potential difference is formed between different knowledge subjects [29], and the proportion of high-level knowledge increases with the increase of functional level. Grassroots workers have operational knowledge which is knowledge and skills for specific business production and operation. Middle-level and senior workers need to have corresponding management knowledge and decision-making knowledge to achieve business objectives for organization's sustainable development. Therefore, high knowledge zone and low knowledge zone are formed between two groups (showed as
Figure 3). Knowledge structure is convertible and can be transformed into capacity structure in human resource management practice. Fayol's study on the competency structure of employees in enterprises argues that the competency structures of employees vary with their positions. The ability requirements of grassroots personnel depend on organizational characteristics. Grass-roots workers should have the technical ability. The technical ability proportions required for workers, director of the team, and director of the workshop are $85 \%, 60 \%$ and $45 \%$ respectively. Middle-level leaders need to satisfy higher requirements for management ability. The proportions of management ability required for president, minister and general manager are $60 \%, 50 \%$ and $50 \%$ respectively [30]. In practice, the technical ability is transformed from the 
business function knowledge, while the management ability

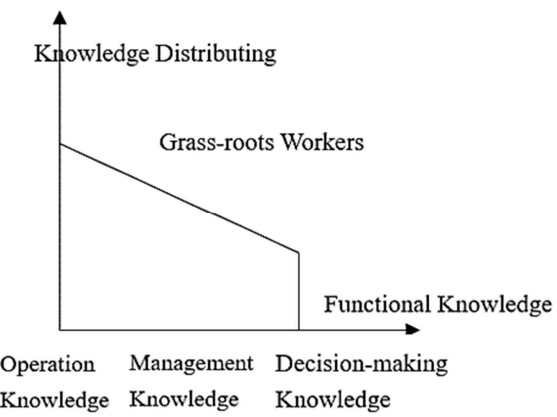

is transformed from the management function knowledge.

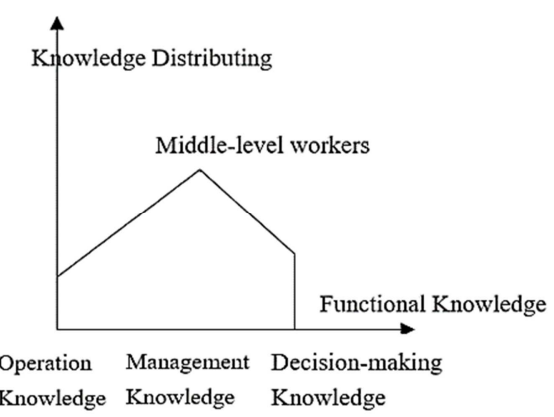

Figure 3. Functional knowledge distribution of workers at different functional levels.

\subsection{Environmental Knowledge Dimension}

Environmental knowledge dimension is the knowledge regarding environments owned by human resources. This dimension can effectively compensate for the lack of fit between training and system environment in the past. From micro to macro scale, the environmental knowledge dimension is specifically divided into seven categories of knowledge related to environments. They are as follows.

\subsubsection{Position Environment}

Specific position environmental knowledge is composed of working conditions, position requirements and other factors of the specific positions.

\subsubsection{Position Related Environment}

Position related environment is composed of working relationships and interpersonal relationships among related positions within organization. In government and public institutions, it is reflected among relevant positions in a same administration office. In enterprises, it is reflected among various professions in a same workshop. In position related environment, there is communication and collaboration among positions (showed in Figure 4), which requires the organizational human resource knowledge system to consider the connection among the positions. The application of the rotation system also puts forward higher requirements for the construction of organizational human resources knowledge, which requires communication and learning among positions in different fields.
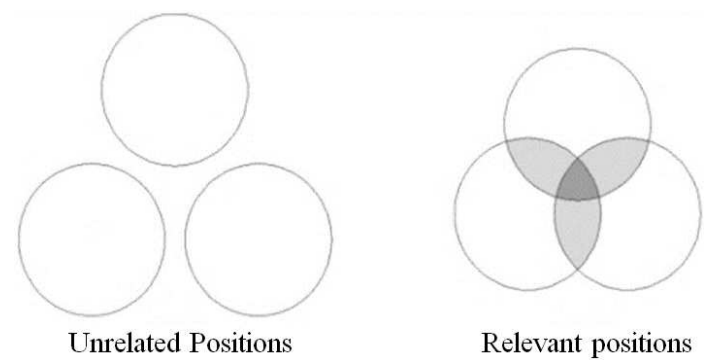

Relevant positions

Figure 4. Position relationship environment.

\subsubsection{Departmental Environment}

The departmental environment of departments in governmental organs and companies in enterprise organizations is composed of position environment and position related environment.

\subsubsection{Organizational Environment}

In government and public institutions, the bureau and provincial departments constitute their organizational environment. In enterprises, the whole company constitutes its own organizational environment. Organizational environment is closely related to organizational culture, vision, and missions.

\subsubsection{Professional Environment}

Different groups are committed to different professional areas, so the human resources of corresponding professional areas also need different environmental knowledge.

\subsubsection{Industry Environment}

It refers to the environmental conditions of different groups engaged in the target industry, including the development of the industry, the impact of major events at home and abroad on the industry, industry trends and other specific elements.

\subsubsection{Social Environment}

Social environment is the most complex environment, covering social and political environment, economic environment, legal environment, cultural environment, technological environment, etc. The first four environmental factors constitute the internal environment faced by organizations, which is about human resources, material resources, financial resources, technical resources and other factors. They are affected by organizational vision, architecture, strategic planning. The latter three environmental factors constitute the external environment, in which the social environment is the general environment faced by organizations. Professional environment and industry environment are special environments for organizations, made up with suppliers, customers, competitors, governments and social groups.

According to the functional level, the environmental knowledge dimension can be divided into operational environmental knowledge, management environmental knowledge and strategic decision-making environmental knowledge. Operational environmental knowledge includes position, position related, and departmental environmental knowledge. Management environmental knowledge includes knowledge of organizational and professional environments. 
Strategic decision-making environmental knowledge consists of industry and social environmental knowledge. The environmental knowledge required by grass-roots workers, middle-level workers and senior workers in the organization is in accordance with the trapezoidal distribution, yamagata distribution and trapezoidal distribution (showed as Figure 5). Grassroots workers focus on the application of position operational knowledge and skills. They know and master more about position environmental knowledge and have
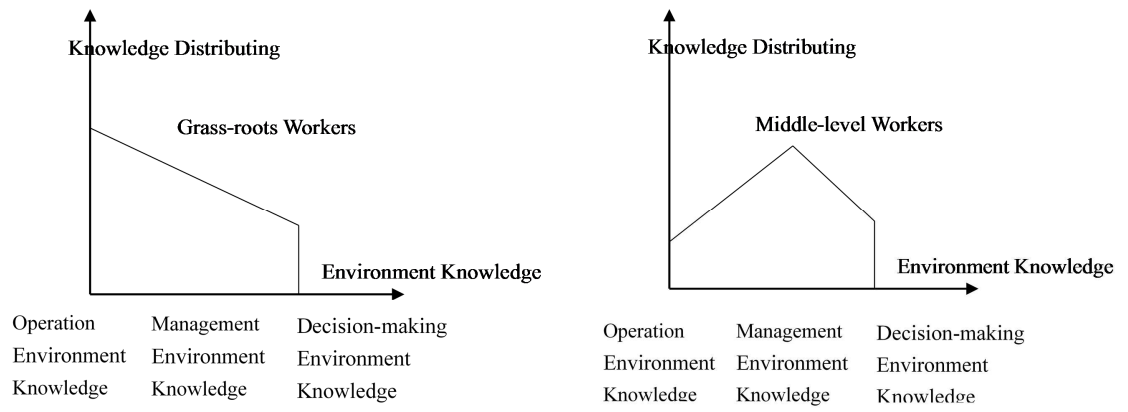

highest requirement for operational environmental knowledge. Middle-level managers focus on management outcomes of the organization, and they have the highest requirements for the management environmental knowledge which is closely related to organizations' development. Senior workers serve to realize organizational strategic objectives, so they need to analyze the macro social environment and master the strategic decision-making environmental knowledge closely related to organizations' development.

Figure 5. Environmental knowledge distribution of workers at different functional levels.

\subsection{Process Knowledge Dimension}

Process knowledge dimension refers to the corresponding process knowledge that employees in different processes should master. Process can be divided into product management process, operational management process and strategic management process according to different focus [31]. Product management process focuses on the specific operational level of organization and production management, such as the process from raw materials to finished products. Employees in this process need to have specific business production and operational knowledge and skills. Operational management process helps organizations to achieve daily functions. It requires human resources in this process to have stronger predictive ability and scientific planning ability, and to concern the efficiency and effectiveness of business management. Knowledge about organizational coordination
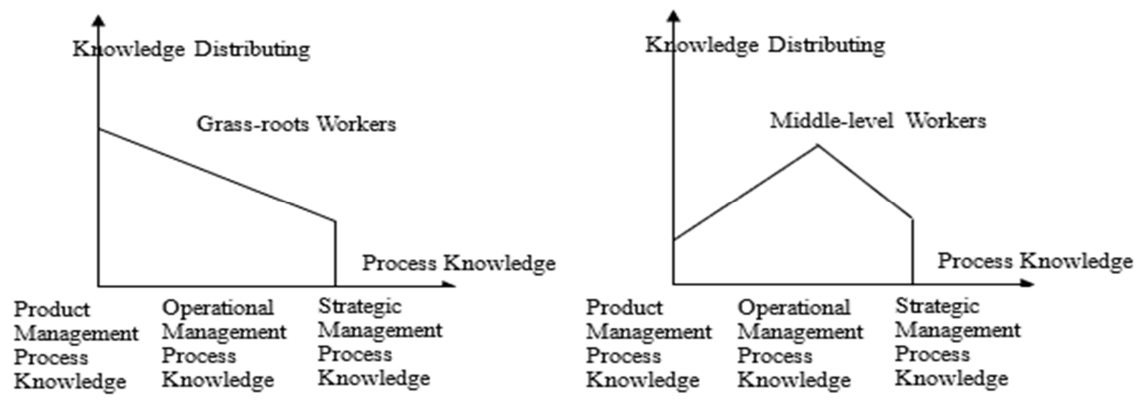

Figure 6. Process knowledge distribution of workers at different functional levels.

\subsection{Logical Knowledge Dimension}

Logical knowledge dimension is the knowledge about business logic. It is needed by human resources to engage in and handle different business processes, and to make correct decisions based on certain environmental conditions. Both "Yuan Heng Li Zhen" and PDCA cycle are the embodiment of ability, planning arrangement ability and communication ability based on management responsibility and notion is necessary for employees in this process. The strategic process serves the whole enterprise level and each business process, concerns global resources optimization disposition, creates sustainable competitive advantage, and pursues the maximization of organizational long-term value. The personnel working on this process need to satisfy the requirements of overall organization, coordination, permanence, and risk prevention. They need to have strategic thinking, overall vision and strong strategic functional knowledge. The requirements of different process knowledge for grassroots workers, middle-level workers and high-level workers also show the characteristics of trapezoidal distribution, yamagata distribution and trapezoidal distribution (showed in Figure 6).

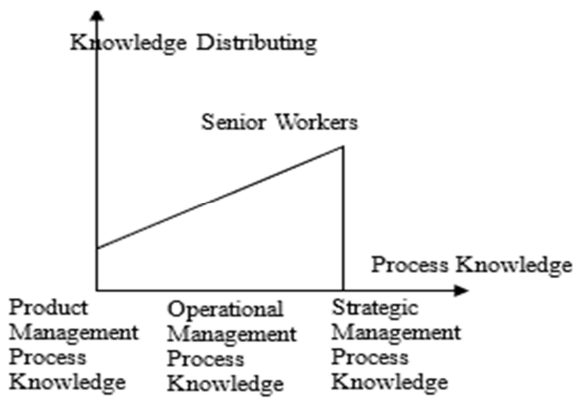

logical thinking framework. "Yuan Heng Li Zhen" is the four virtues in Book of Changes, "Yuan" means the originating, referring to the starting point and purpose. "Heng" means access and success. "Li" means the unity of all things, representing interest. "Zhen" means just, firm and lasting. These virtues together reflect the process of infinite changes in the cycle of things $[32,33]$. PDCA cycle is a cycle process that 
includes four stages of planning, implementation, reviewing and settling. Each cycle is closely linked to form a logical idea for continuous improvement. The logical knowledge dimension of human resource knowledge system is formed by integrating "Yuan Heng Li Zhen" with PDCA logic, containing seven logical stages.

\subsubsection{Setting Clear Objectives}

Corresponding to the "Yuan" in the four virtues, "Yuan" is the starting point and purpose of organization development. Human resources should clarify the strategic objectives and ultimate goal of the organization to guide the follow-up work.

\subsubsection{Feasibility Analysis}

Feasibility analysis corresponds to "Heng" for access and success. Under the organizational objectives of different stages, human resources management conducts feasibility analysis based on existing and potential resources in order to ensure its supportive role in achieving organizational objectives.

\subsubsection{Value Judgment}

"Li" of the four virtues means interest and value, and it is different between self-interest and altruism. For organizations, value judgement is the judgement made by human resources to forecast economic and social benefits based on the organization's development plan at different stages. It requires to realize the unity of organizational goals and social responsibilities.

\subsubsection{Sustainability Analysis}

It is the reflection of "Zhen", which means sustainability. Human resources management are required to analyze the sustainability of organizational development goals and plans.

\subsubsection{Comparison}

Mapping from the "reviewing" process in the PDCA cycle, it requires a comparative analysis ahead of the schemes' implementation for their advantages and disadvantages based on organizational goals and stage characteristics, in order to achieve program optimization.
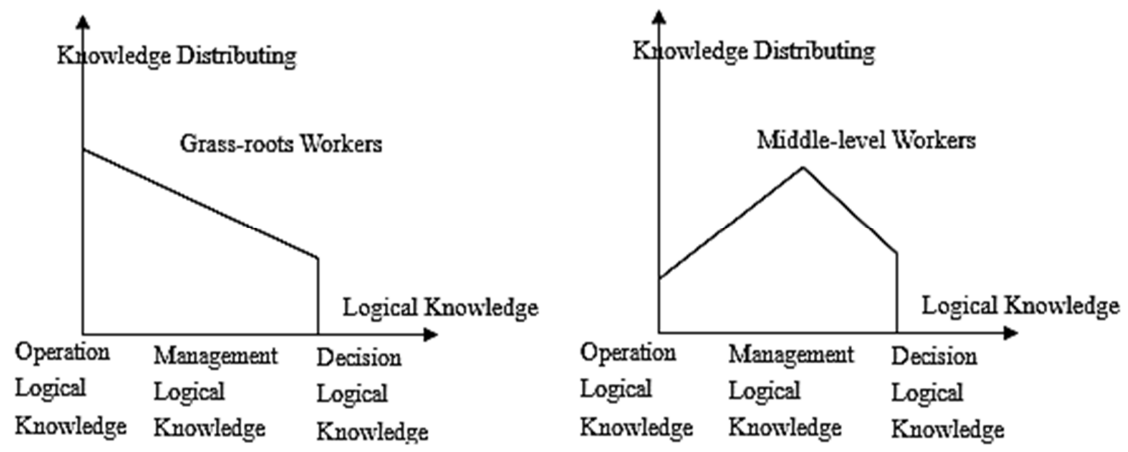

Figure 7. Logical knowledge distribution of workers at different functional levels.

\subsection{The Relationship Among the Dimensions of the Four-Dimensional Structure Model}

Based on the analysis above, it is necessary to comprehensively analyze the knowledge structure of human resources based on the four-dimensional structure system, so

\subsubsection{Decision Making}

It corresponds to the "P" phase of PDCA cycle. Based on comparative optimization, it is to select a satisfactory implementation scheme suitable for realizing organizational goals.

\subsubsection{Formulating Execution Plan}

Corresponding to the "D" phase of PDCA cycle, a particular scheme, and then specific operations are carried out.

According to its components, logical knowledge dimension can be divided into operational logical knowledge, management logical knowledge and decision logical knowledge, corresponding to its organizational functional level. The decision logical knowledge is necessary for senior managers, including clear organizational strategic objectives, goal setting after overall consideration of feasibility and social responsibilities, value judgment, and sustainability analysis. The management logical knowledge is essential for middle-level workers. It requires them to master the knowledge to compare and select the best solutions to achieve organizational goals. Operational logical knowledge is what grass-roots workers should have, which is to implement the plan and carry out specific operations based on the formulation of the execution plan. The requirements of different logical knowledge for grass-roots workers, middle-level workers and trapezoidal distributions respectively.

However, due to the minor differences among individuals' logical knowledge, the distribution difference of this knowledge dimension is also smaller than other knowledge dimensions. Grassroots workers are good at specific operational knowledge and pay more attention to micro logical thinking. Middle-level workers are most proficient in management logical knowledge. Senior personnel need to coordinate the interests of organization, societies and individuals and determine organizational strategic objectives based on organizational missions, purpose and vision. Thus, they have more macro decision-making logical knowledge (showed in Figure 7). execution plan is formulated according to the predetermined senior workers conform to trapezoidal, yamagata and

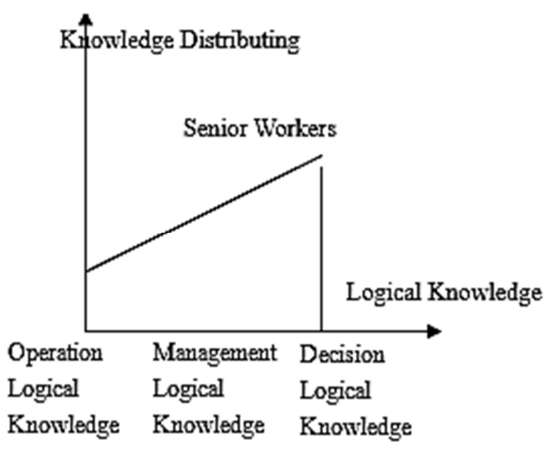

as to determine the content, plans and schemes for human resources training. It is important to combine with functional levels to determine the knowledge needed in the functional knowledge dimension, to concern the process knowledge corresponding to different processes, to fully consider the 
internal and external environment faced by organizations, and to take the process stage in the logical knowledge dimension into account. Only in this way can we construct the knowledge structure of organizational human resources from a global and systematic perspective, and realize the coordination and optimization of the organizational human resources knowledge structure. The relationships among dimensions of the four-dimensional structure model are showed in Figure 8.

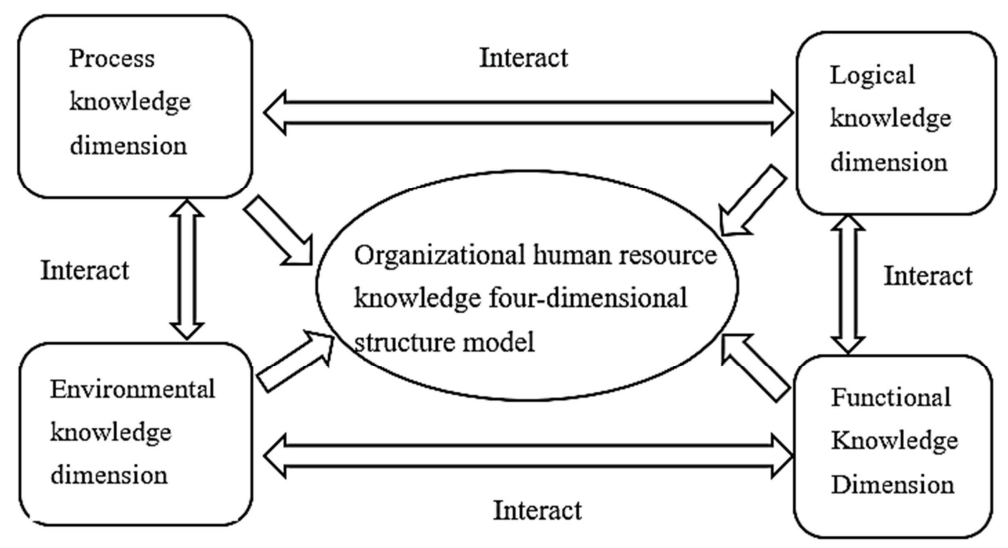

Figure 8. Organizational human resource knowledge four-dimensional structure diagram.

\section{The Significance of Organizational Human Resource Four-Dimensional Knowledge Structure Model}

The four-dimensional structure model constructs a knowledge structure system that human resources should master from functional level knowledge, process knowledge, environmental knowledge and logical knowledge, which is universal in the actual operation of human resource management. It plays a guiding role in methodology for organizations to carry out knowledge management depending on different knowledge needs in diverse environments and development stages. Thus, human resource knowledge management, development and training activities differ on positions, individuals, and time. It contributes to a systematic and dynamic framework for the construction of human resource knowledge system for organizations.

The four-dimensional structure model divides the dimension of logical knowledge into seven stages in order to clarify the logical thinking to utilize the relevant human resources knowledge for organizations. It defines the logical thinking knowledge content of human resources in different stages, and helps organizations adjust and determine the required logical thinking knowledge according to the actual situation and functional characteristics of human resources.

Environmental dimension helps organizations adjust the knowledge content of human resource selection and training in time according to the changes of internal and external environment and their own development needs. It also enables organizations to update the human resource knowledge based on the changes of environment.

The four-dimensional structure model clarifies the knowledge differences among organization members with the existence and distribution characteristics of knowledge potential. Organizations can refer to the contents of E-F, E-P and P-L to make clear what knowledge the human resources are missing, and then work out particular plans to offset and improve.

Organizational human resources knowledge can be acquired by learning, training and other approaches. In practice, the knowledge of organizational human resources is usually transformed into the ability of human resources. The knowledge structure of human resources is transformed into ability structure through practice and showed as quality structure. Therefore, building a scientific and reasonable knowledge structure system for human resources is important in organizational development.

Table 2. Specific application of organizational human resource four-dimensional knowledge structure model in human resource selection, training and development.

\begin{tabular}{|c|c|}
\hline Dimension & The specific operation of human resource training and development in different dimensions \\
\hline $\begin{array}{l}\text { Functional knowledge } \\
\text { dimension }\end{array}$ & $\begin{array}{l}\text { The weights of decision knowledge, management knowledge and operational knowledge are represented by a } \%, b \% \text { and } c \% \\
\text { respectively. The functional knowledge required by grass-roots workers is } \mathrm{a} \%<\mathrm{b} \%<\mathrm{c} \% \text {. The weight } \mathrm{b} \% \text { of management } \\
\text { knowledge required by middle-level workers is the largest; the distribution of functional knowledge required by senior workers } \\
\text { is } \mathrm{a} \%>\mathrm{b} \%>\mathrm{c} \% \text {. }\end{array}$ \\
\hline $\begin{array}{l}\text { Environmental } \\
\text { knowledge dimension }\end{array}$ & $\begin{array}{l}\text { Decision environmental knowledge, management environment knowledge and operational environment knowledge are } \\
\text { represented by } \mathrm{a} \%, \mathrm{~b} \% \text { and } \mathrm{c} \% \text { respectively. Environmental knowledge required by grass-roots workers is } \mathrm{a} \%<\mathrm{b} \%<\mathrm{c} \% \text {. The } \\
\text { weight } \mathrm{b} \% \text { of management environmental knowledge required by middle-level workers is the largest, and the distribution of } \\
\text { environmental knowledge required by senior workers is } \mathrm{a} \%>\mathrm{b} \%>\mathrm{c} \% \text {. }\end{array}$ \\
\hline $\begin{array}{l}\text { Process knowledge } \\
\text { dimension }\end{array}$ & $\begin{array}{l}\text { The weights of strategic management process knowledge, business management process knowledge and production } \\
\text { management process knowledge are expressed by } \mathrm{a} \%, \mathrm{~b} \% \text { and } \mathrm{c} \% \text { respectively. The process knowledge required by grassroots } \\
\text { workers is } \mathrm{a} \%<\mathrm{b} \%<\mathrm{c} \% \text {. The weight } \mathrm{b} \% \text { of management process knowledge required by middle-level workers is the largest; } \\
\text { the process knowledge required by senior workers is } \mathrm{a} \%>\mathrm{b} \%>\mathrm{c} \% \text {. }\end{array}$ \\
\hline
\end{tabular}




\begin{tabular}{ll}
\hline Dimension & The specific operation of human resource training and development in different dimensions \\
\hline $\begin{array}{l}\text { Logical knowledge } \\
\text { dimension }\end{array}$ & $\begin{array}{l}\text { The weights of decision logical knowledge, management logical knowledge and operation logical knowledge are represented by } \\
\mathrm{a} \%, \mathrm{~b} \% \text { and } \mathrm{c} \% \text { respectively. The logical knowledge required by grass-roots workers is } \mathrm{a} \%<\mathrm{b} \%<\mathrm{c} \% \text {. The weight } \mathrm{b} \% \text { of } \\
\text { management logical knowledge required by middle-level workers is the largest. The distribution of logical knowledge required } \\
\text { by high-level workers is } \mathrm{a} \%>\mathrm{b} \%>\mathrm{c} \% .\end{array}$ \\
$\begin{array}{l}\text { In the process of human resource selection and training, we should comprehensively consider the role of these four knowledge dimensions in the construction } \\
\text { of organizational knowledge system. The organization should analyze its own characteristics, environment, functional level and the business process to form } \\
\text { the indicator system of the organizational human resources knowledge structure about a certain position. In practice, the weights of knowledge mastered by }\end{array}$ \\
$\begin{array}{l}\text { workers at all levels, and the specific content and secondary indicator division of each knowledge dimension that different workers need master should be } \\
\text { determined by experts in relevant fields. }\end{array}$
\end{tabular}

\section{Conclusion}

The organizational human resources knowledge structure is influenced by its business function, business process, business processing logic and environment. Based on the four-dimensional structure system from system engineering methodology, this paper constructs an organizational human resource knowledge four-dimensional structure model, and thoroughly explains the connotation of four dimensions. It points out the existence of human resource knowledge potential differences among various functional levels, environmental conditions, business processes and business processing logic stages. Furthermore, each knowledge dimension of grassroots workers, middle-level workers and senior workers in organizations obey trapezoidal distribution, yamagata distribution and trapezoidal distribution successively. When applying the organizational HRKFDM, the model can be easily transformed into an indicator system of organizational human resource knowledge structure, and then experts can determine the specific weights of different knowledge dimensions in the indicator system. According to the organizational strategic goals, the specific knowledge content and distribution weight of the four-dimensional knowledge structure can be specified combined with experts' comprehensive experiences and judgment. The model can provide systematic guidance for organizational human resources selection and training, and additionally form a dynamic knowledge structure indicator system framework with the interaction and evolution of functional levels, environmental conditions, processes, and mind-sets. The four-dimensional knowledge structure model can be used as an important reference framework for promoting organizational learning, building a learning organization, and constructing core competence within organizations.

\section{References}

[1] Wernerfelt B. A. (1984). Resource-Based View of the Firm. Strategic Management Journal. (5): 171-180.

[2] Spencer L M.. Spencer S M. (1993). Competence at Work: Models for Performance. London: John Wiely. 222-226.

[3] Zhao Shuming. Du Juan. (2007). A study of human resource management based on competency model. Economic Management Journal. 29 (6): 16-22. (In Chinese).

[4] Zhang Qing. (2009). A study of recruitment and selection of human resources based on competency. Journal of Industrial Technological Economy. 28 (9): 107-112. (In Chinese).

[5] Wang Chongming. Chen Minke. (2002). Managerial competency modeling: a structural equation testing. Psychological Science. 25 (5): 513-516. (In Chinese).

[6] Li Hongwei. (2012). A five-dimensional quality model for enterprise personnel selection. Mall modernization. (32): 142. (In Chinese).

[7] Chen Yueru. Ma Nan. (2007). The core standard analysis of organizational human resources selection. Shopping mall modernization. (30): 314. (In Chinese).

[8] Liao Ming. (2008). Establish a hierarchical classification of human resources planning system. Human resources development of China. (2): 20-23. (In Chinese).

[9] Zhao Shuming. (2002) Human resources management and planning. Beijing: China Renmin University Press. 250 - 151. (In Chinese).

[10] Li Ying (2009). Promotion of SME training and development model and organizational competitiveness. Journal of Southwest Minzu University. 30 (1): 136-139. (In Chinese).

[11] Li Shumin. Shikan. (2009). Training demand analysis based on competency $[\mathrm{J}]$. Human resources development of China. (3): 49-51. (In Chinese).

[12] Li Hua. (2011). Enterprise training based on organization ability and individual ability. Human resource management. (1): 41. (In Chinese).

[13] Shao Xinyao. (2015). On Performance Improvement: From the Perspective of Training. Value Engineering. (34): 72-73. (In Chinese).

[14] Yoichi Matsumoto. (2013). Heterogeneous Combinations of Knowledge Elements: How the Knowledge Base Structure Impacts Knowledge-related Outcomes of a Firm. Discussion Paper. (15): 1-36.

[15] Zahra S A. George G. (2002). Absorptive capacity: A review, re-conceptualization and extension. Academy of Management Review, 27 (2): 185-203.

[16] Qian Jianping. (2013). Research on the knowledge structure and training mode of intellectual property talents. Chinese University Teaching. (11): 33-36. (In Chinese).

[17] Liu Guangzhu. Duan Xingmin. Chen Wenli. (2004). Research on the knowledge structure of enterprise managers. Gansu Social Sciences. (6): 236 - 238. (In Chinese).

[18] Wang Hao. (2014). The research and exploration of periodical librarians 'knowledge structure in digital times A case study of university libraries in Nanjing area. Library and Information. (1): 24-29. (In Chinese). 
[19] Yang Lin. (2010). Analysis of Acting Mechanisms on the Relationship among Entrepreneurial Cognition, Organizational Knowledge Structure and Corporation Strategic Change. Science of Science and Management of S. \&. T. 31 (12): 67-69. (In Chinese).

[20] Wang Wan. Wu Sizong. (2011). Knowledge-intensive service organization core competence analysis based on knowledge structure. Scienc e\& technology progress and Policy. 28 (4): 14-17. (In Chinese).

[21] Dong Guangmao. Rao Yushuang. (2015). Research on the relationship between knowledge structure and innovation performance in the complex and dynamic environment. Journal of Xi'an Technology University. (3): 243-248. (In Chinese).

[22] Huiping Zhou, Karen Yuan Wang, Yanhong Yao, Kai-Ping Huang. (2019) The moderating role of knowledge structure in the open innovation effect. Management Decision. 57 (9): 2223-2238.

[23] Lei Zhanbo. Xi Youmin. (2001). On the four-dimensional morphology of system engineering methodology. Systems Engineer-Theory Methodology Applications. 10 (2): 116-120. (In Chinese).

[24] Lei Zhanbo. Xi Youmin. (2001). The Application Research of Four-Dimensional Morphology in the Process of Information System Development. System Engineering. (6): 78- 83. (In Chinese).

[25] Lei Zhanbo. Shi Zeyuan. (2017). Research on Process Model of Organization of Human Resource Management Based on the System Engineering Methodology. Journal of Tianjin University (Social Science). (3): 193-197. (In Chinese).

[26] Yang B, Zheng W, Viere C. (2009) Holistic views of knowledge management models [J]. Advances in Developing Human Resources. (3): 273-289.

[27] Yang B. (2003) Toward a holistic theory of knowledge and adult learning [J]. Human Resource Development Review. (2): 106-129.
[28] Patrick J. Montana. by Bruce H. Chanov. (2004). Management. Shanghai: Shanghai Renmin Press. 80-82. (In Chinese).

[29] Du Jing. Wei Jiang. (2004). Analysis of the growth mechanism of knowledge stock. Science of Science and Management of S. \&. T. (1): 24-27. (In Chinese).

[30] Zhu Xiaowei. (2003). Human resources management and development in public sector. Harbin: Heilongjiang Renmin Press. 35. (In Chinese).

[31] J. Pepad. P. Roland. (1999). Business Process Reengineering. Beijing: CITIC Press. 11-15. (In Chinese).

[32] Zhang Liwen. (2020 Yuan Heng Li Zhen One of the Principles of Chinese Philosophy Academic Journal of Zhongzhou. (1): 113-123. (In Chinese).

[33] Yang Ping. (2018) The Translation and Interpretation of Yuan Heng $\mathrm{Li}$ Zhen in the Zhouyi Journal of Zhejiang of international studies University. (6): 78-83 (In Chinese).

\section{Biography}

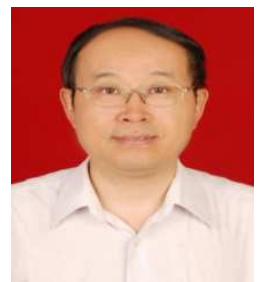

Lei Zhanbo received the PH.D. degree in Management from Xi'an Jiaotong University in 1996. Then he stayed for teaching and researching. From 2005 to now he is a professor at School of Public Policy and Administration. $\mathrm{He}$ has wide research interests, mainly including management information system, knowledge management. He published more than 70 papers. He was a visiting associate professor at Tokyo University of Science. In 1996, Based on the three-dimensional structural system of A. D. Hall, he originated the four-dimensional structural system of system engineering methodology and proposed the E-T, E-L matrix, which emphasized the importance of environmental analysis. 